\title{
Properties of Waste Fiber/Polyurethane Flame Retardant Insulation Board
}

\author{
LV, L.H.(LV, Lihua); LIU, Y.J.(LIU, Yingjie); LI, C.T.(LI, Congtan); GUO, J.(GUO, Jing); YE, F.(YE, Fang) \\ School of textile and material engineering, Dalian Polytechnic University, Dalian, P.R.China
}

Corresponding Author: LV Lihua, Ivlh@dlpu.edu.cn

\begin{abstract}
In order to solve the recycling problem of waste fibers, waste fiber/polyurethane flame retardant insulation board was prepared by blending- hot pressing method with waste cotton fiber, discarded polyurethane, AC (azodimethylamide) foaming agent and APP (ammonium polyphosphate) flame retardant as raw materials. The necessary conditions to the optimized technology was mass fraction of waste fibers $10 \%$, mass fraction of AC foaming agent $3 \%$, mass fraction of APP flame retardant $15 \%$, hot pressing pressure $7 \mathrm{MPa}$, hot pressing temperature 180 , length of waste fibers $20 \mathrm{~mm}$, mixing temperature 175-180, hot pressing time $8 \mathrm{~min}$, cool-down time $2 \mathrm{~h}$, which were optimized by thermal conductivity coefficient, limit oxygen index and mechanical properties. The flame retardant mechanism and effect of the waste fiber/polyurethane flame retardant insulation board was analyzed by TGA (Thermogravimetric Analysis) and residual carbon ratio. Finally, the abaqus finite element simulation software was used to simulate the thermal conduction process and verify the correctness of model.
\end{abstract}

\section{ARTICLE HISTORY}

Received: 04.09.2018

Accepted: 13.03 .2019

\section{KEYWORDS}

Waste fiber, flame retardant Insulation board, flame retardant mechanism, finite element simulation, thermal Insulation mechanism

\section{INTRODUCTION}

Now there were more than 26 million tons of discarded textiles in China, but the recycling ratio was less than $10 \%$. It is showed that more than 100 million tons of discarded textiles will be produced by the end of 2020 in China [1-2]. If the average period of clothes was 3-4 years, the discarded ratio of textiles was $70 \%$ [3]. These discarded textiles not only caused horrendous waste, but also got a worse influence on the environment. So, it is imminent to recycle these discarded textiles and manufacture high value-added products. Lv et al. [4] prepared a new type of composite material using discarded duck feathers and ethylene vinyl acetate copolymer (EVA) by lay-up and hot pressing method, which had good sound absorption performance. And theoretical models for the prediction of sound absorption coefficients of composites made of discarded duck feathers were presented. Lv et al. [5] prepared waste corn husk fibers / polylactic acid composite material with ammonium polyphosphate and pentaerythritol as flame retardants by blended hot mastication process. The flame retarded composites made of pre-treated corn husk fibers and polylactic acid with good flame retarded and mechanical properties could be used in building materials, furniture, decorative materials and other fields. Long et al. [6] fabricated natural fibers reinforced high density polyethylene (PE-HD) composites with ramie noil from textile industry and bamboo scrap fibers from paper-making industry as reinforcements, so the waste fibers could be used reasonably. Chen et al. [7] used waste flax fibers as raw material for pyrolysis treatment to study the oil absorption performance. It can be seen that the waste fibers have been reasonably utilized through the efforts of scholars, but there is still a lot of space for the study of waste fibers.

It was shown from the statistics that nearly $30 \%$ of the world's energy consumption was used on constructions. The ratio of China's building energy consumption was more than $27.45 \%$ of the total energy consumption. The emissions ratio of greenhouse gas $\mathrm{CO}_{2}$ caused by the building energy consumption run up to $25 \%$ of China's total greenhouse gas emissions [8-10]. China's new building areas reached 2 billion $\mathrm{m}^{2}$ each year, and there were more than $95 \%$ of them were the high energy consumption buildings [11]. In the building enclosure, the thermal insulation wall occupied the largest proportion in the heating energy consumption, which

To cite this article: Lihua, LV., Liu, Y., Li, C., Guo J., Ye, F. 2019. Properties of waste fiber/polyurethane flame retardant insulation board. Tekstil ve Konfeksiyon, 29(2), 152-161. 
accounted for the $32 \%-36 \%$ of the total energy consumption [12]. Now, the ratio of good thermal insulation building wall materials used to reduce energy consumption was about $25 \%-51 \%$ [13]. At present, the insulation materials used in building enclosure structure are mainly insulation mortar and insulation board. At present, there were many kinds of insulation boards, among which fiber-reinforced composite insulation boards had the advantages of light weight, high strength, good thermal insulation performance, high bonding strength, good fireproof performance, weather resistance, etc. They not only overcome the disadvantages of expanded perlite boards such as high water absorption rate, decreased thermal insulation effect in the later period and easy hollowing and cracking, but also made up for the defects of polystyrene foam boards such as poor durability, flammability, poor fireproof performance, harmful gas generation at high temperature, etc. [14]. In addition, compared with polystyrene particle thermal insulation mortar, fiber reinforced composite thermal insulation board solved the problem that polystyrene particle thermal insulation mortar was not suitable for construction in winter and avoided the mixing construction of workers on site. Panyakaew and Fotios [15] used cocoanut shell and bagasse to prepare the lightweight insulation board by hot pressing method and studied the mechanical properties and thermal insulation properties of insulation boards with different density. Then, the thermal conductivity coefficient was $0.046-0.068 \mathrm{~W} / \mathrm{m}^{*} \mathrm{~K}$ under the densities of 250 $350 \mathrm{~kg} / \mathrm{m}^{2}$. Cai et al. [16] prepared sisal fiber/phenolic resin insulation board and studied the compressive strength, impact strength and thermal conductivity. Zhao [17] proposed the "phonon eutectic" theory to reduce the thermal conduction of materials and form a green and efficient thermal insulation board-SIB (Smart Insulation Board). Zhu [18] prepared $\mathrm{SiO}_{2}$ aerogel core/polystyrene flame retardant insulation board with excellent thermal insulation properties (thermal conductivity coefficient was $0.026 \mathrm{~W} /\left(\mathrm{m}^{*} \mathrm{~K}\right)$ ) and good mechanical properties. With all kinds of exterior wall insulation boards flooding the market, we should vigorously develop new fiber-reinforced composite insulation boards with light weight, high strength, thermal insulation, fire resistance, strong durability and environmental protection. Polyurethane, known as the "fifth largest plastic", it was widely used in architectural, automotive, petrochemical, textile, electronic, mechanical, medicine and other fields [19]. In the aspect of polyurethane composites, Ding et al. [20] prepared the wood fiber/polyurethane foam reinforced composites and the thermal conductivity coefficient was $0.017 \mathrm{~W} /\left(\mathrm{m}^{*} \mathrm{~K}\right)$. Yu et al. [21] used waste polyester fiber to enhance thermoplastic polyurethane, and developed the sound absorption composites. Chen et al. [22] made polyurethane-based warp-knit spacer fabric composites with excellent sound-absorbing properties using flexible polyurethane foams.
The purpose of this study is to reduce the harm of waste fibers and improve the performance of thermal insulation composites. In this paper, waste cotton fiber, discarded polyurethane, AC foaming agent and APP flame retardant were used as raw material. Then, waste fiber/polyurethane flame retardant insulation board was prepared by blendinghot pressing method. The optimized technological conditions were obtained according to the thermal conductivity coefficient, limit oxygen index and mechanical properties. The flame retardant mechanism and thermal insulation mechanism of the waste fiber/polyurethane flame retardant insulation board were analyzed by TGA, residual carbon ratio, average diameter of bubble pores were observed by SEM. Finally, the abaqus finite element simulation software was used to simulate the thermal conduction process.

\section{EXPERIMENTAL}

\subsection{Materials}

Waste cotton fibers obtained by opening waste fabrics (provided by Dalian Ganjingzi Huicheng Cotton Product Factory), discarded polyurethane (provided by Bayer Co., Ltd.), azodimethylamide (provided by Yuyao Tong Yong Plastic Dyeing Co., Ltd.) and ammonium polyphosphate (provided by Jinan Taixing Fine Chemical Co., Ltd.) were used. The material composition table was shown in Table 1.

\subsection{Instrument}

QJK1000A Leftover Material Opening Machine which was from Qingdao Jingmengke Machinery Manufacturing Co, Ltd. was used for opening; SJK-180 Double Roll Plasticizer which was from Wuhan Yiyang Plastic Machinery Co., Ltd. was used for mixing and plasticizing; QLB-50D/QMN Pressure Molding Machine which was from Jiangsu Wuxi Zhongkai Plastic Machinery Co., Ltd. was used for forming; ZHY-W Universal Prototype which was from Hebei Chengde Testing Machine Factory was used for the preparation of testing samples; RGY-5 Microcomputer Control Electronic Universal Testing Machine which was from Shenzhen Regal Instrument Co., Ltd. was used for testing mechanical properties; KES-F7 Tester which was from Hunan Zhenhua Analysis Instrument co., Ltd. was used for measuring thermal properties; LFY-606B Digital Display Limit Oxygen Index Measuring Instrument which was from Shandong Textile Science Research Institute was used for measuring limit oxygen index; JSM-6460LV Scanning Electron Microscope which was from Japan was used for observing surface morphology; STAPT1600 Thermogravimetric Analyzer which was from Germany Lineis was used for testing the relationship between material temperature and quality; Muffle which was from Beijing Original Technology Co., Ltd. was used for hot processing.

Table 1. Material composition table

\begin{tabular}{ccccc}
\hline $\begin{array}{c}\text { Compositions of the } \\
\text { samples }\end{array}$ & $\begin{array}{c}\text { Waste cotton } \\
\text { fiber }\end{array}$ & $\begin{array}{c}\text { Discarded } \\
\text { polyurethane }\end{array}$ & Azodimethylamide & $\begin{array}{c}\text { Ammonium } \\
\text { polyphosphate }\end{array}$ \\
\hline Code & $\mathrm{A}$ & $\mathrm{B}$ & $\mathrm{C}$ & $\mathrm{D}$ \\
Level 1 & $10 \%$ & $90 \%$ & $1 \%$ & $10 \%$ \\
Level 2 & $20 \%$ & $80 \%$ & $2 \%$ & $15 \%$ \\
Level 3 & $30 \%$ & $70 \%$ & $3 \%$ & $20 \%$ \\
\hline
\end{tabular}

(Note: The mass fractions of azodimethylamide and ammonium polyphosphate were relative to discarded polyurethane.) 


\subsection{Preparation process}

The waste fiber/polyurethane flame retardant insulation board was prepared by blending-hot pressing method with waste fibers, discarded polyurethane particles, AC foaming agent and APP flame retardant as raw materials. The average length of waste cotton fibers was $20 \mathrm{~mm}$, blending temperature was $175-180$, hot pressing time was $8 \mathrm{~min}$, cool-down time was $2 \mathrm{~h}$ and the thickness of the resultant insulation boards was $1 \mathrm{~cm}$. The specific preparation process of waste fiber/polyurethane flame retardant insulation board was shown in Fig.1.

\subsection{Detection indexes}

\subsubsection{Thermal conductivity coefficient}

The thermal conductivity coefficient was test according to $\mathrm{GB} / \mathrm{T}$ 10295-2008. The thermal conductivity coefficient (1) is:

$$
K=\frac{(Q \times D)}{(A \times \Delta T)}
$$

In the formula: $\mathrm{K}$ is the thermal conductivity coefficient, the unit is $W /\left(m^{*} K\right) ; Q$ is the heat loss, the unit is $W ; D$ is the thickness of specimen, the unit is $m$; $A$ is the area of specimen, the unit is $\mathrm{m}^{2} ; \Delta \mathrm{T}$ is the temperature difference, the unit is $\mathrm{K}$.

Substances with high thermal conductivity coefficient had excellent thermal conductivity. For thermal insulation materials, the thermal conductivity coefficient was lower and the insulation performance was better. Generally, materials with a thermal conductivity coefficient of less than $0.2 \mathrm{~W} /\left(\mathrm{m}^{*} \mathrm{~K}\right)$ were called thermal insulation materials.

\subsubsection{Limit oxygen index}

The limit oxygen index was test according to GB/T89242005. The limit oxygen index was higher and the flame retardant perform was better. When the limit oxygen index was $22-25 \%$, the material had the property of selfextinguishment; when the limit oxygen index was $26 \%$, the material was flame retardant and the flame retardant property was well when the limit oxygen index reached $30 \%$.

\subsubsection{Mechanical properties}

The testing standard and method of tensile properties were according to GB/T 1447-2005 - Test method for tensile properties of fiber-reinforced plastics. And the testing standard and method of bending properties were according to GB/T 1449-2005 - Test method for bending properties of fiber-reinforced plastics.

\subsubsection{Thermogravimetric curve and residual carbon ratio}

Thermogravimetric curve was according to GB/T 277612011 - Standard test method of mass loss and residue measurement validation of thermogravimetric analyzers. The testing standard and method for testing residual carbon rate were according to GB/T27761-2011. The details were as follows: a certain amount of sample was taken into the crucible and dried for $2 \mathrm{~h}$. And then, they were taken out and weighed $m_{0}$. The dried samples and crucible were put into the muffle, and the temperature of the muffle was set at 600 . When the heating was finished, the weight of the samples and the crucible were $m_{1}$, the quality ratio of $m_{0}$ and $m_{1}$ was the residual carbon ratio. The higher the carbon residue rate was, the less gaseous substances would be produced at high temperature. Also, the formed carbon layer covered the surface of the polymer and improved the heat and corrosion resistance.

\subsubsection{Diameter of bubble pores}

Diameter of bubble pores was measured by the average chord length method. Then, the average diameter of bubble pores $\mathrm{D}$ was obtained by formula (2), during this process, the bubble pores could be regarded as homogeneous sphere.

$$
d=\frac{L}{0.785^{2}}=\frac{L}{0.616}
$$

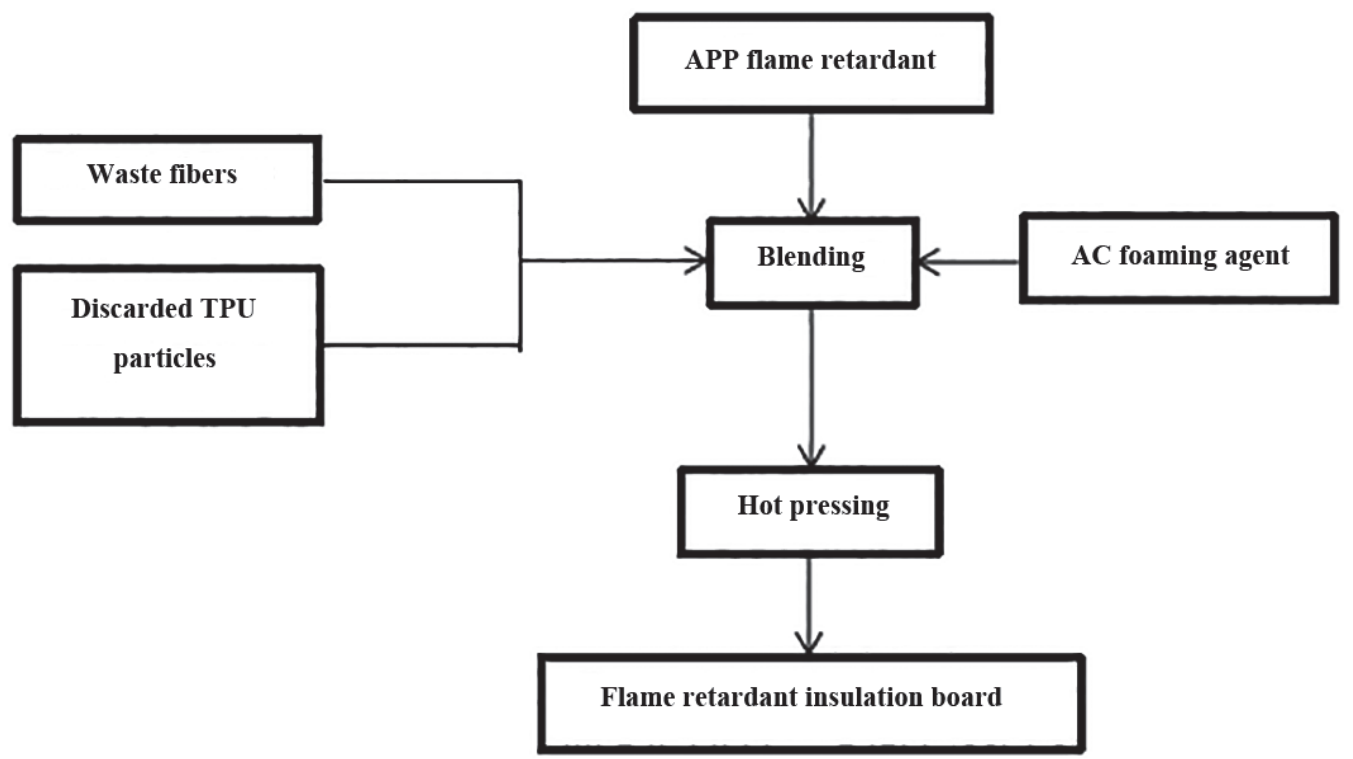

Figure 1. Specific preparation process 
In the formula: $d$ is the average diameter of the bubble pores, the unit is $\mu \mathrm{m}$; $L$ is the average chord length of the bubble pores, the unit is $\mu \mathrm{m}$.

\section{RESULTS AND DISCUSSION}

3.1 Optimized Technological Conditions of Waste Fiber/Polyurethane Flame Retardant Insulation Board

\subsubsection{Effect of mass fraction of waste fibers on thermal conductivity coefficient $K$ and limit oxygen index $\mathrm{LOI}$}

The mass fraction of waste fibers was $10,20,30 \%$ and other technological parameters were as follows: hot pressing temperature 180 , hot pressing pressure $5 \mathrm{MPa}$, mass fraction of flame retardant $20 \%$, mass fraction of foaming agent $2 \%$, length of waste fibers $20 \mathrm{~mm}$, mixing temperature 175-180, hot pressing time $8 \mathrm{~min}$, cool-down time $2 \mathrm{~h}$. The effect of the mass fraction of waste fibers on the thermal conductivity coefficient $\mathrm{K}\left(10^{-2} \mathrm{~W} /\left(\mathrm{m}^{*} \mathrm{~K}\right)\right)$ and the limit oxygen index LOI were shown in Fig.2.

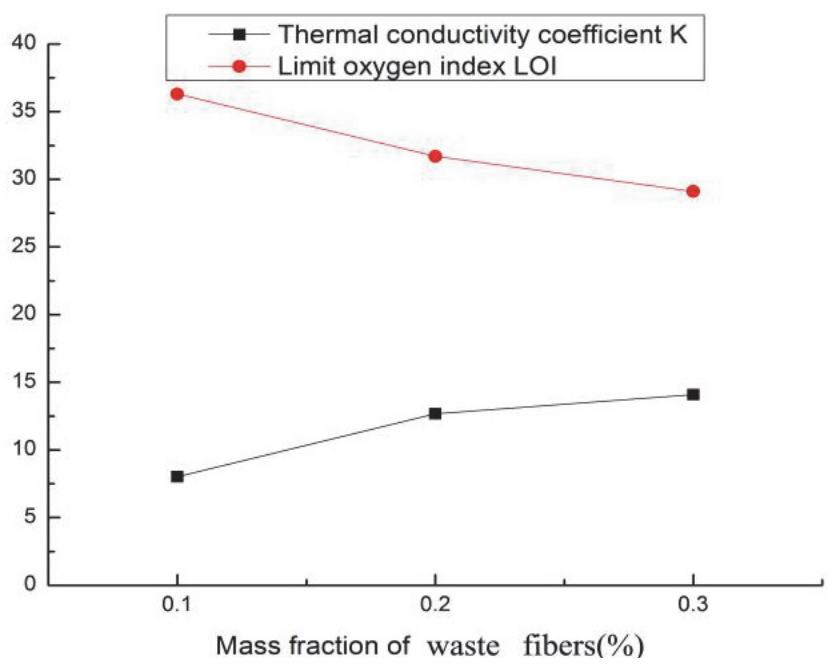

Figure 2. Effect of mass fraction of waste fibers on thermal conductivity coefficient $\mathrm{K}$ and limit oxygen index LOI

It was seen from Fig. 2 that the mass fraction of waste fibers had significant effect on thermal conductivity coefficient and limit oxygen index. The mass fraction of waste fibers was higher, the thermal conductivity coefficient became greater and the limit oxygen index was smaller. That was to say, with the increasing of the mass fraction of waste fibers, the thermal insulation properties and the flame retardant properties of the thermal insulation board got worse. The reasons might be as follows: with the increasing of the mass fraction of waste fibers, there were more difficulties in blending and the viscosity was increased. So, the resistance of bubble pores was increased and it was easy to damage the structure of bubble pores [23], which the formation of bubble pores were affected. Therefore, the thermal insulation properties of the thermal insulation board were decreased. For the flame retardant properties, the sealing of carbon layer in the process of APP flame retardants was destroyed for excessive waste fibers and oxygen could not be completely isolated, so the flame retardant properties of the thermal insulation board were affected. Therefore, the mass fraction of waste fibers was sure of $10 \%$.

\subsubsection{Effect of hot pressing temperature on thermal conductivity coefficient $K$ and limit oxygen index LOI}

The hot pressing temperature was 170, 180, 190 and other technological parameters were as follows: mass fraction of waste fibers $10 \%$, hot pressing pressure $5 \mathrm{MPa}$, mass fraction of flame retardant $10 \%$, mass fraction of foaming agent $2 \%$, length of waste fibers $20 \mathrm{~mm}$, mixing temperature 175-180, hot pressing time $8 \mathrm{~min}$, cool-down time 2 h.The effect of hot pressing temperature on the thermal conductivity coefficient $\mathrm{K}\left(10^{-2} \mathrm{~W} /\left(\mathrm{m}^{*} \mathrm{~K}\right)\right)$ and the limit oxygen index LOI were shown in Fig. 3.

It was seen from Fig. 3 that hot pressing temperature had significant influence on thermal conductivity coefficient and limit oxygen index. When the temperature was about 170 to 190 , with the increase of hot pressing temperature the limit oxygen index raised first and then decreased and the thermal conductivity coefficient decreased first and then increased. When the hot pressing temperature was 170 , the effective decomposition temperature of the foaming agent could not be reached, so the effective cell structure could not be formed, thus the heat preservation property was reduced. When the hot pressing temperature was 190 , the decomposition speed of foaming agent was too fast and it resulted in partial overheating for the release of a large amount of heat. So it was easy to destroy the bubble pore structure or form the opened bubble pores which were not conducive to the formation and stability of closed bubble pores, and the thermal insulation properties would also decrease. When the hot pressing temperature was 180 ,the thermal insulation properties and the flame retardant properties of the thermal insulation board were best, so the hot pressing temperature could be determined to 180 .

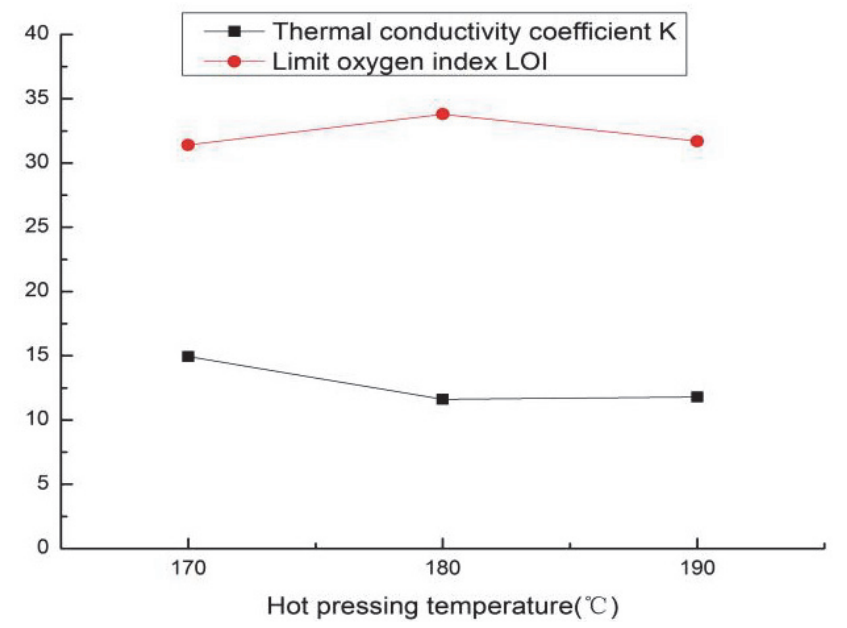

Figure 3. Effect of hot pressing temperature on thermal conductivity $\mathrm{K}$ and limit oxygen index LOI

\subsubsection{Effect of mass fraction of flame retardant on thermal conductivity coefficient $K$ and limit oxygen index $\mathrm{LOI}$}

The mass fraction of flame retardant was $10,15,20 \%$, and the other technological parameters were as follows: mass fraction of waste fibers $10 \%$, hot pressing temperature 180 , hot pressing pressure $5 \mathrm{MPa}$, mass fraction of foaming agent $2 \%$, length of waste fibers $20 \mathrm{~mm}$, mixing temperature 
175-180, hot pressing time $8 \mathrm{~min}$, cool-down time $2 \mathrm{~h}$. Effect of mass fraction of flame retardant on thermal conductivity coefficient $\mathrm{K}\left(10^{-2} \mathrm{~W} /\left(\mathrm{m}^{*} \mathrm{~K}\right)\right)$ and limit oxygen index LOI were shown in Fig.4.

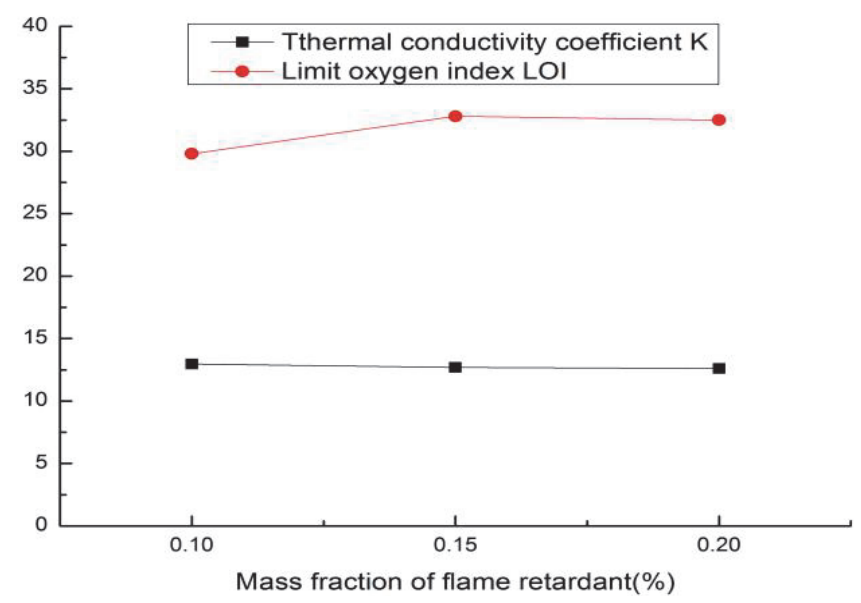

Figure 4. Effect of mass fraction of flame retardant on thermal conductivity coefficient $\mathrm{K}$ and limit oxygen index LOI

It was seen from Fig.4 that mass fraction of the flame retardant had little influence on the thermal conductivity coefficient, but it had obvious effect on the limit oxygen index. When the mass fraction of the flame retardant was in the range of $10 \%$ to $20 \%$, with the increased of the mass fraction of the flame retardant, the limit oxygen index was increased. However, when the mass fraction of flame retardants was greater than $15 \%$, the increasing trend of the limit oxygen index could reduce. So the mass fraction of flame retardant was $15 \%$.

3.1.4 Effect of mass fraction of foaming agent on thermal conductivity coefficient $K$ and limit oxygen index LOI

The mass fraction of the AC foaming agent was $1,2,3 \%$, and the other technological parameters were as follows: mass fraction of waste fibers $10 \%$, hot pressing temperature 180 , hot pressing pressure $10 \mathrm{MPa}$, mass fraction of flame retardant $15 \%$, length of waste fibers $20 \mathrm{~mm}$, mixing temperature 175-180, hot pressing time $8 \mathrm{~min}$, cool-down time $2 \mathrm{~h}$. Effect of mass fraction of foaming agent on thermal conductivity coefficient $\mathrm{K}\left(10^{-2} \mathrm{~W} /\left(\mathrm{m}^{*} \mathrm{~K}\right)\right)$ and limit oxygen index LOI were shown in Fig.5.

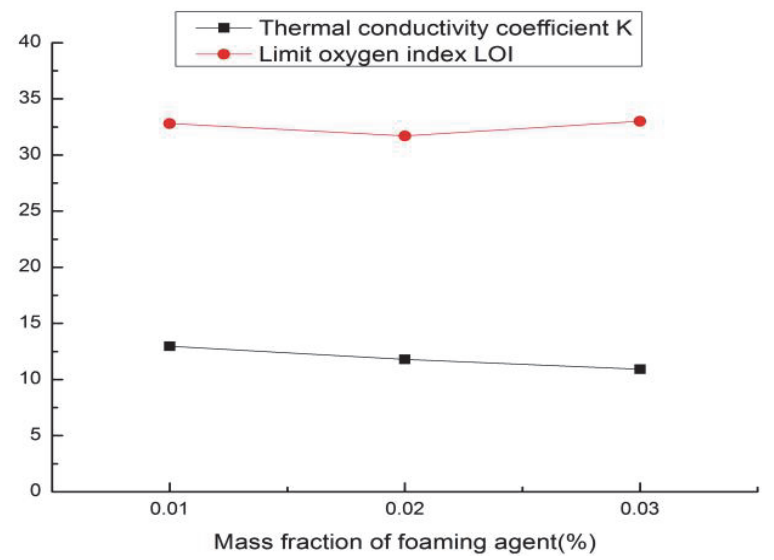

Figure 5. Effect of mass fraction of foaming agent on thermal conductivity coefficient $\mathrm{K}$ and limit oxygen index LOI
It was seen from Fig. 5 that the mass fraction of the foaming agent had little effect on the limit oxygen index, but it had great influence on the thermal conductivity coefficient. With the increase of the mass fraction of the foaming agent, the thermal conductivity coefficient decreased and the thermal insulation properties were good. The reasons were as follows: the mass fraction of the foaming agent was low, the produced gas by decomposition was less, and the bubble pores were less. With the increased of the mass fraction of the foaming agent, the nucleation rate of the bubble pores increased and the more bubble pores were formed, so the thermal conductivity coefficient decreased and the thermal insulation properties were good. Then, the mass fraction of the foaming agent was $3 \%$.

\subsubsection{Effect of hot pressing pressure on thermal conductivity coefficient $K$ and limit oxygen index LOI}

The hot pressing pressure was 4, 7, $10 \mathrm{MPa}$, and the other technological parameters were as follows: mass fraction of waste fibers $10 \%$, hot pressing temperature 180 , mass fraction of flame retardant $15 \%$, mass fraction of foaming agent $3 \%$, length of waste fibers $20 \mathrm{~mm}$, mixing temperature 175-180, hot pressing time $8 \mathrm{~min}$, cool-down time $2 \mathrm{~h}$. Effect of hot pressing pressure on thermal conductivity coefficient $\mathrm{K}\left(10^{-2} \mathrm{~W} /\left(\mathrm{m}^{*} \mathrm{~K}\right)\right)$ and limit oxygen index LOI were shown in Fig.6.

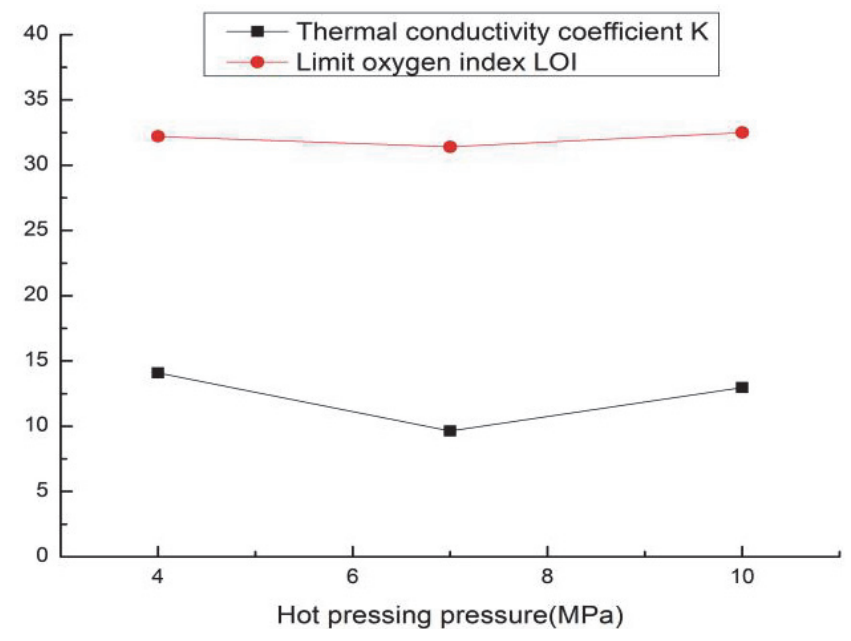

Figure 6. Effect of hot pressing pressure on thermal conductivity coefficient $\mathrm{K}$ and limit oxygen index LOI

It was seen from Fig.6 that the hot pressing pressure had no effect on the limit oxygen index, but had a great influence on the thermal conductivity coefficient. When hot pressing pressure was too high or too low, the thermal conductivity coefficient was large and the thermal insulation properties were bad. Therefore, the hot pressing pressure was suitable for $7 \mathrm{MPa}$. When the hot pressing pressure was smaller, it was easy to cause the smaller solubility of gas, the wall of bubble pores was thick and the distribution of bubble pores was not uniform. So, the thermal conductivity coefficient was larger. When the hot pressure was too high, the gas diffusion ratio was so large and the escaped gas was too much, and it could not form the homogeneous structure of bubble pores. So, the thermal conductivity coefficient was larger. Meanwhile, the unloading pressure could also cause the excessive gas to gush out of the molten body and it 
caused the failure of fabrication of the flame retardant insulation board. Then, the hot pressing pressure was suitable for $7 \mathrm{MPa}$.

The necessary conditions to the optimized technology was mass fraction of waste fibers $10 \%$, mass fraction of $A C$ foaming agent $3 \%$, mass fraction of APP flame retardant $15 \%$, hot pressing pressure $7 \mathrm{MPa}$, hot pressing temperature 180 , length of waste fibers $20 \mathrm{~mm}$, mixing temperature 175-180 , hot pressing time $8 \mathrm{~min}$, cool-down time $2 \mathrm{~h}$. And, under the optimized technological conditions, the waste fiber/polyurethane flame retardant insulation board has good thermal insulation properties, flame retardation and mechanical properties. The thermal conductivity coefficient was $0.06 \mathrm{~W} /\left(\mathrm{m}^{*} \mathrm{~K}\right)$, the limit oxygen index was $35.82 \%$, the tensile strength was $2.642 \mathrm{MPa}$, and the bending strength was $5.314 \mathrm{MPa}$.

\subsection{Flame Retardant and Thermal Insulation Mechanism Analysis of Flame Retardant Insulation Board}

\subsubsection{Flame retardant mechanism analysis}

\section{(1) Analysis of thermogravimetric curve}

The thermogravimetric curve of the thermal insulation board under the optimized technological conditions was shown in Fig.7. From Fig.7, it could be seen that the initial degradation temperature was about 268 and the end degradation temperature was about 500 . The degradation ratio decreased obviously in 400 . The initial degradation temperature of TPU was about 261 , by contrast, the initial degradation temperature (268) of the waste fiber/ polyurethane flame retardant insulation board was improved. So, the effect of APP on flame retardation was obvious. The role of APP flame retardant was divided into three stages: release of ammonia, catalytic carbonization and decomposition of polyphosphoric acid chain. Research showed that the phosphorus content in APP was relatively high. Nitrogen in APP could catalyze phosphide to form phosphoric acid rapidly, and then thermally polymerize into polyphosphoric acid. In the combustion process, due to the strong dehydration effect of polyphosphoric acid, the polymer was effectively dehydrated into carbon. The formed non-combustible glassy substance covered the surface of the system and isolated oxygen and combustible gas, thereby reducing the feedback heat of flame and the degradation reaction degree of the substrate and realizing the flame retardant effect [24].

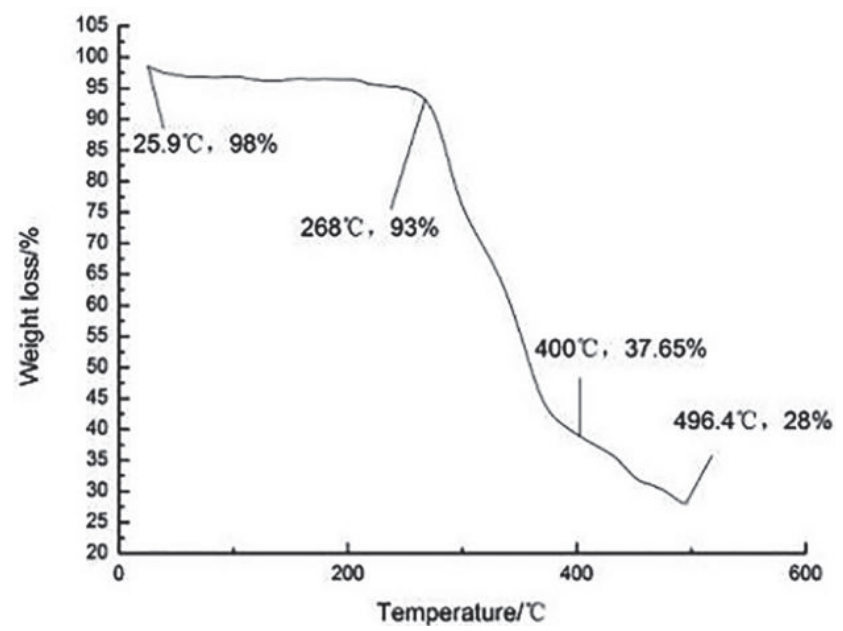

Figure 7. Thermal Weightlessness curve

(2) Analysis of residual carbon ratio

The pictures of residual carbon were shown in Fig.8, in which $8 a$ was the residual carbon picture with none flame retardant, and $8 \mathrm{~b}$ was the residual carbon picture under the optimized technological conditions.

The residual carbon ratio of 8 a was $24.5 \%$, 8 b was $39.2 \%$. It could be clearly seen from Fig. 8 that the carbonized layer of the waste fiber/polyurethane flame retardant insulation board prepared by the optimized technological conditions was better than the sample without flame retardant, which indicated that the APP flame retardant obtained good flame retardant effect on the flame retardant insulation board.
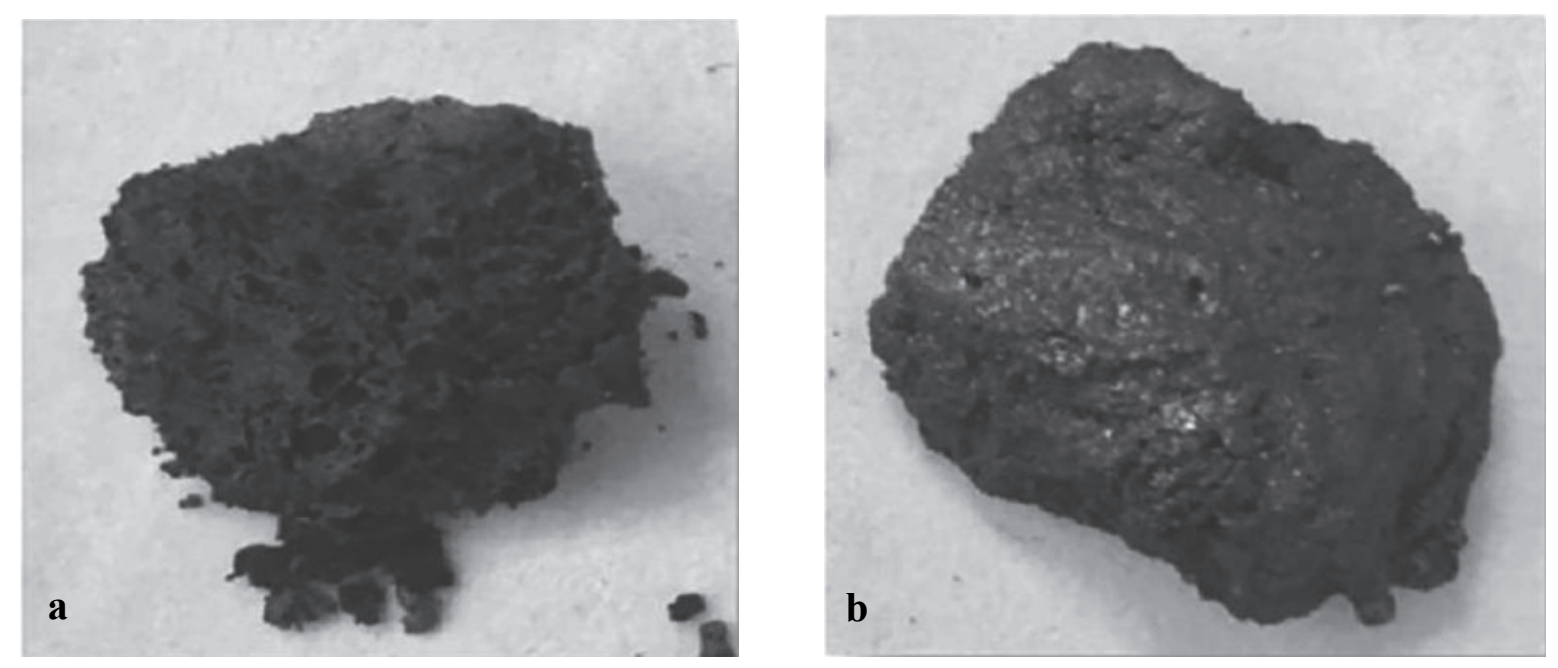

Figure 8. The pictures of residual carbon a. Without flame retardant, b. With flame retardant 


\subsubsection{Thermal insulation mechanism analysis}

The scanning electron microscope of the waste fiber/polyurethane flame retardant insulation board under the optimized technological conditions was shown in Fig.9. Fig.9 showed the bubble pores structure inside the flame retardant insulation board, the magnification of 9a was 50 times, and the magnification of $9 \mathrm{~b}$ was 100 times. Calculated by the Equation (2) in 2.4, the average diameter of bubble pores in the waste fiber/polyurethane flame retardant insulation board under the optimized technological conditions was $350 \mu \mathrm{m}$. It could be seen from Fig. 9 that the waste fiber/polyurethane flame retardant insulation board had good and uniform bubble pores, mostly closed bubble pores, thin walls of the bubble pores, rounded shape of the bubble pores, so it had the excellent thermal insulation properties.

\section{FINITE ELEMENT ANALYSIS OF THERMAL CONDUCTION OF WASTE FIBER/POLYURETHANE FLAME RETARDANT INSULATION BOARD}

\subsection{Create Geometry}

According to the measured sample specification $(100 * 100 *$ $10 \mathrm{~mm}$ ), the geometry of the waste fiber/polyurethane flame retardant insulation board was established.

\subsection{Material Properties}

The material properties of the waste fiber/polyurethane flame retardant insulation board were determined by the measured performances and homogenization theories of equivalent elastic modulus and equivalent thermal conductivity coefficient. The material properties of the waste fiber/polyurethane flame retardant insulation board were shown in Table 2.

\subsection{Establish Analytical Steps, Contact, Load and Meshing}

The type of analysis was steady state thermal conduction analysis. According to measured conditions, the ambient temperatures on both sides of the waste fiber/polyurethane flame retardant insulation board were 30 and 20. And the mesh unit type was DC3D8 in ABAQUS software. The meshing model was shown in Fig. 10.

\subsection{Temperature Distribution Nephogram}

The job was submitted for monitoring and analysis, and entered the visualization after the job was completed. The temperature distribution nephogram of the waste fiber/polyurethane flame retardant insulation board was shown in Fig. 11 and the side temperature distribution nephogram was shown in Fig.12.
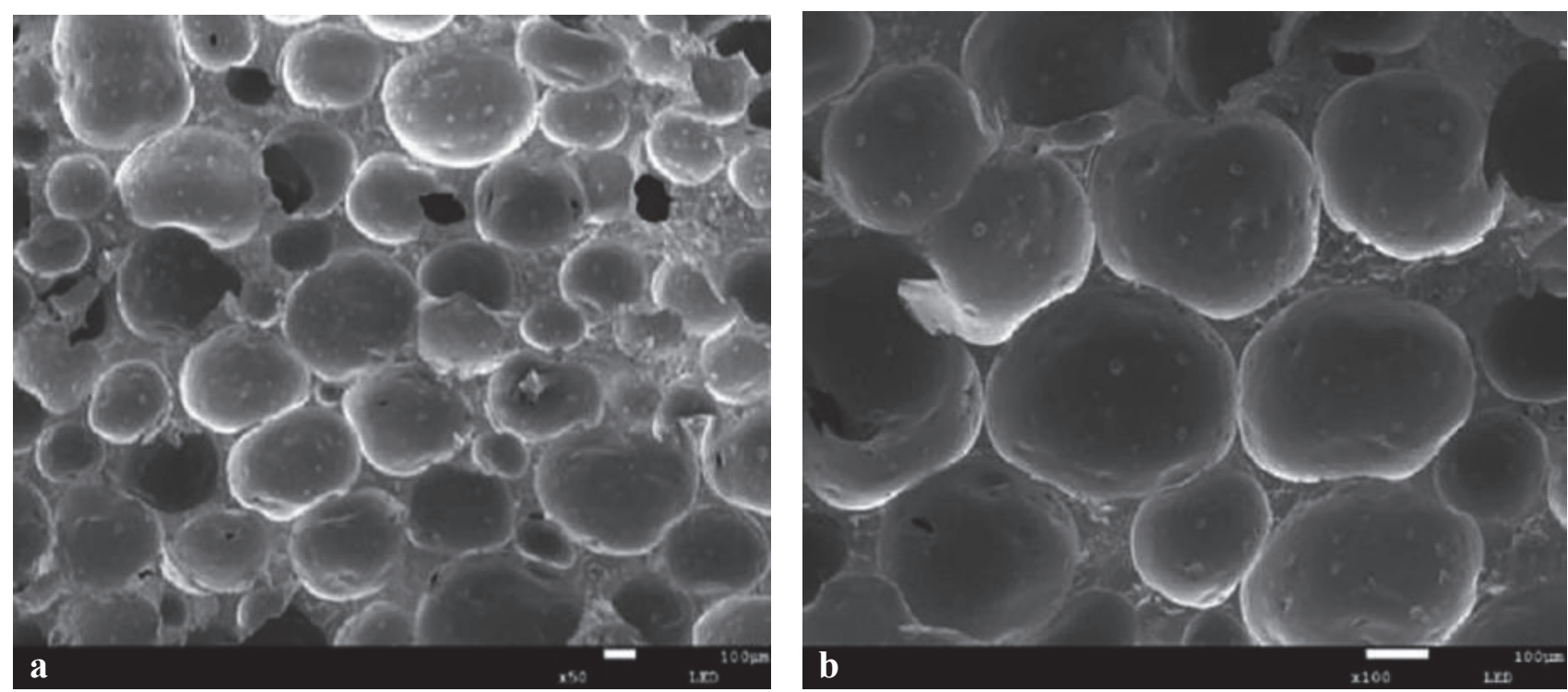

Figure 9. The scanning electron microscope of the waste fiber/polyurethane flame retardant insulation board a. The magnification of 50 times, b. The magnification of 100 times

Table 2. Material properties of thermal insulation board

\begin{tabular}{ccccc}
\hline $\begin{array}{c}\text { Density } \\
\left(\mathrm{g} / \mathrm{cm}^{3}\right)\end{array}$ & Poisson ratio & $\begin{array}{c}\text { Young modulus } \\
\mathrm{MPa})\end{array}$ & $\begin{array}{c}\text { Specific heat } \\
\left(\mathrm{J} / \mathrm{g} \cdot{ }^{\circ} \mathrm{C}\right)\end{array}$ & $\begin{array}{c}\text { Thermal conductivity } \\
\mathrm{W} /(\mathrm{m} \cdot \mathrm{K})\end{array}$ \\
\hline 0.484 & 0.4 & 21.6 & 2800 & 0.06 \\
\hline
\end{tabular}




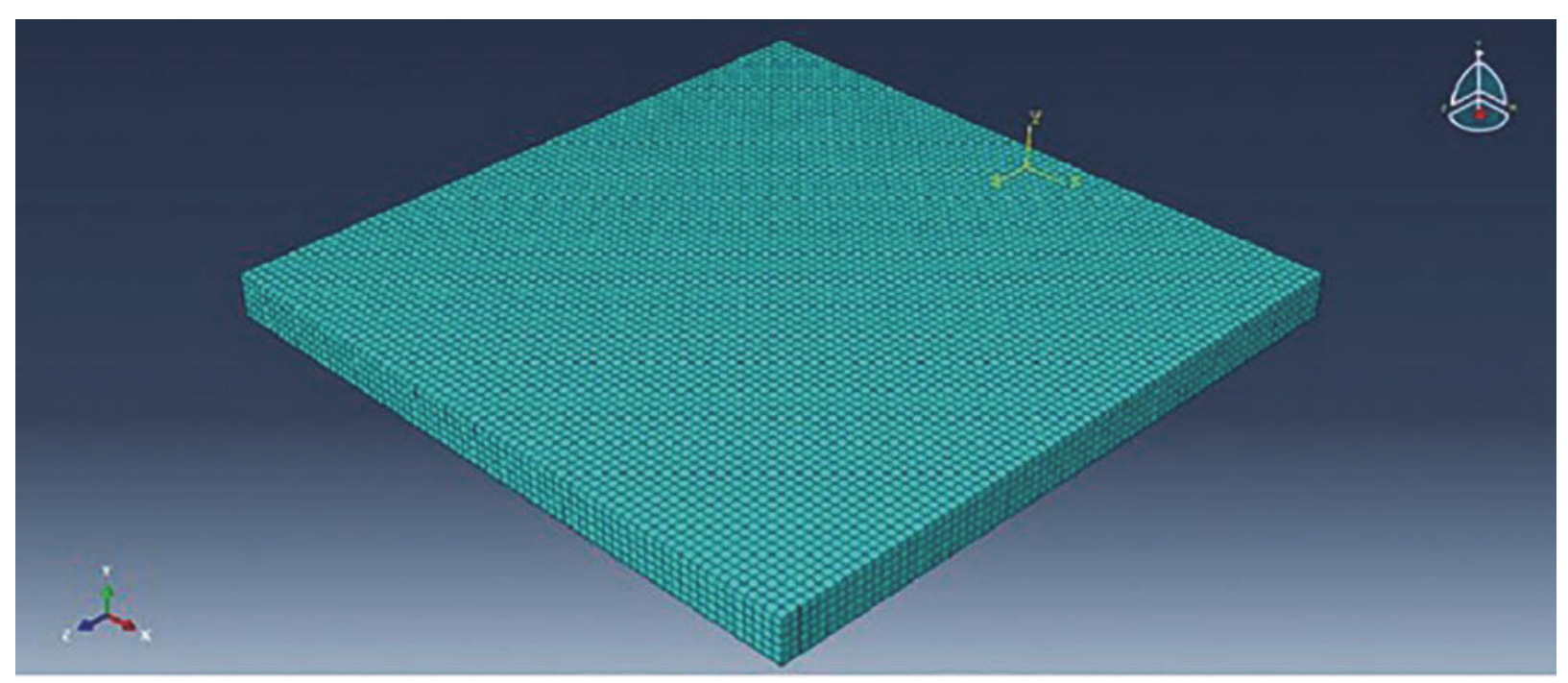

Figure 10. Gridding model
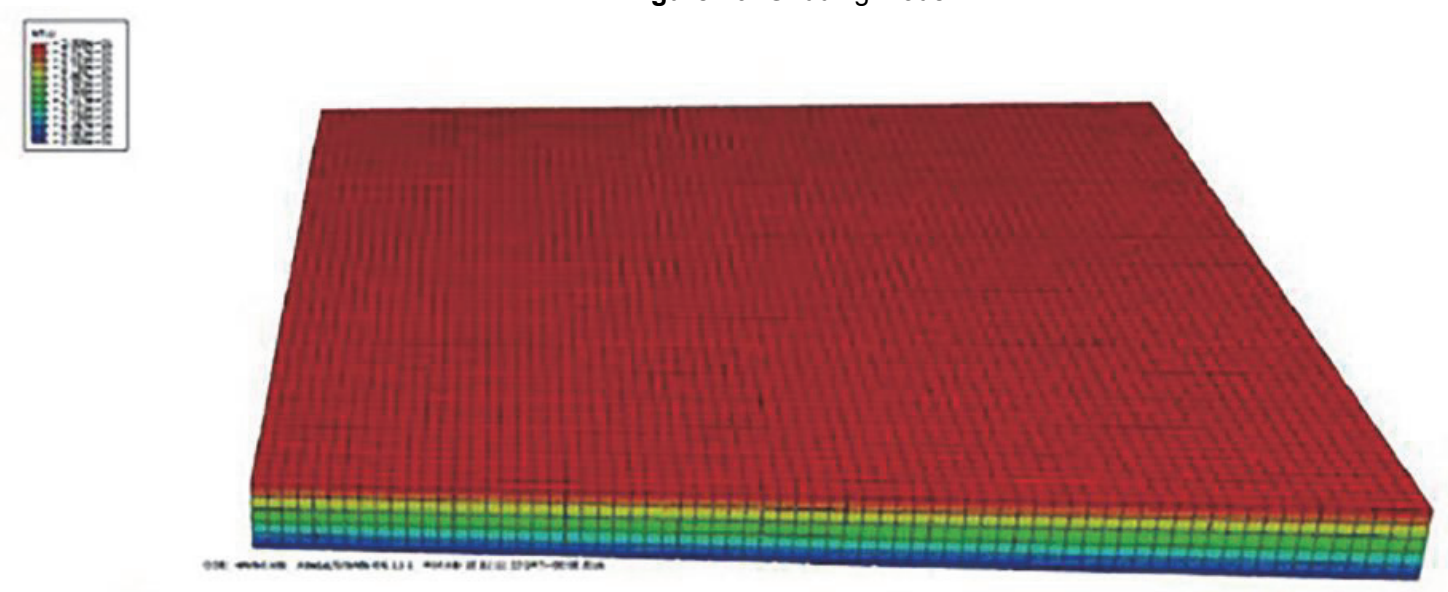

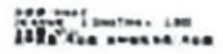

Figure 11. Temperature distribution nephogram thermal of insulation board

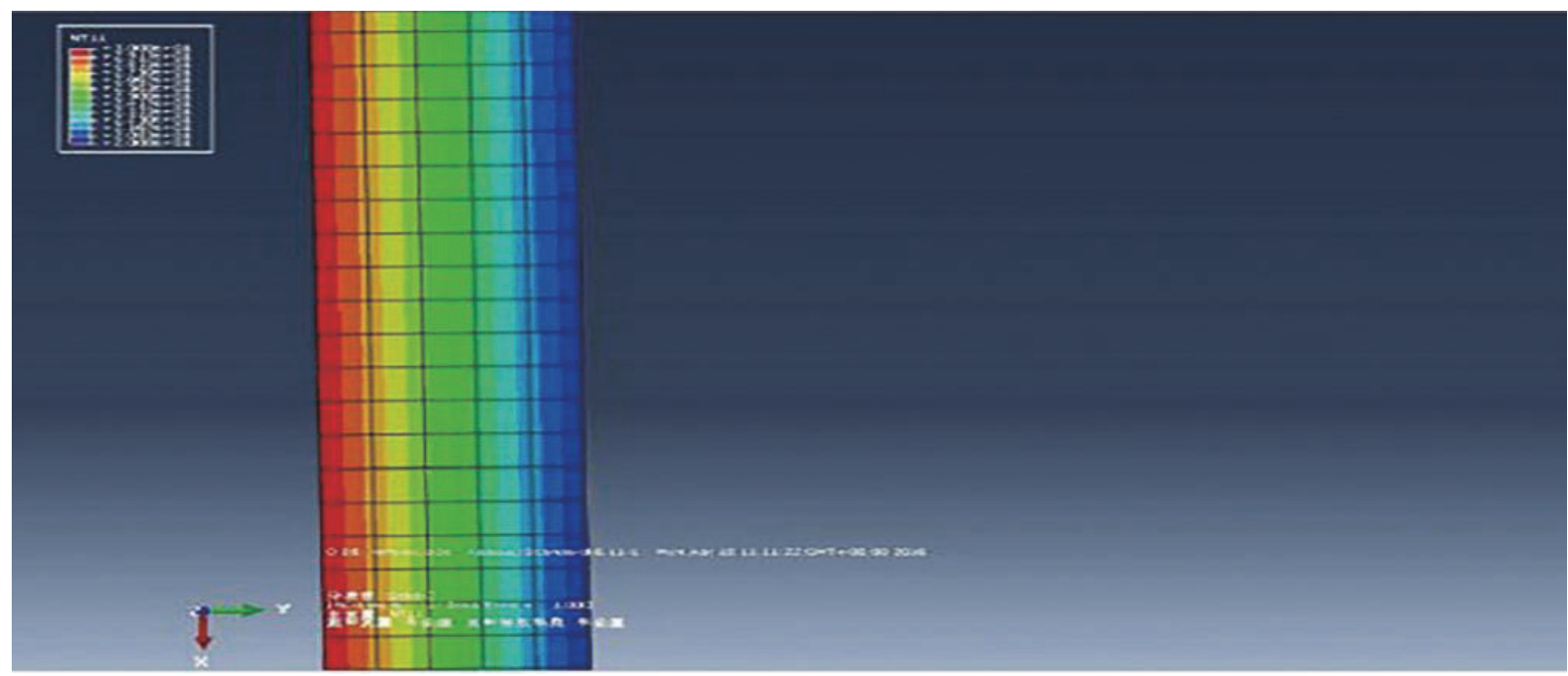

Figure 12. Side temperature nephogram

From the temperature distribution nephogram of the model, it could be seen that the heat transfer process was uniform. After the thermal conduction process was over, the temperatures of the two sides were 27.5 and 22.9. The thermal loss was calculated according to Equation (3), 


$$
Q=\frac{K \times A(T-t)}{D}
$$

where, $Q$ is thermal loss; $K$ is thermal conductivity coefficient; $A$ is the surface area of sample; $D$ is thickness of the sample; $\mathrm{T}, \mathrm{t}$ is the temperature on both sides of the sample;

The thermal loss of the material was $0.276 \mathrm{~W}$ when the simulated data were taken in the Equation (3).

Through KES-F7, the thermal loss of the waste fiber/polyurethane flame retardant insulation board was $0.27 \mathrm{~W}$. And the simulated thermal loss was basically the same as the measured thermal loss. It could be inferred that the actual and simulated thermal conduction processes of the waste fiber/polyurethane flame retardant insulation board were consistent. Under the actual test conditions, it was very difficult to test the actual temperature distribution nephogram of the material. And through the simulation of ABAQUS finite element software, we could not only get the temperature distribution nephogram, but also solved the temperature change under different ambient temperature conditions. It was helpful for designing the technological parameters of the thermal insulation board to analyze the temperature change in the simulation process.

\section{CONCLUSION}

The waste fiber/polyurethane flame retardant insulation board had been prepared by blending-hot pressing method with waste cotton fibers, discarded polyurethane, $A C$ foaming agent and APP flame retardant as raw materials. And the following conclusions were drawn:

1. Through single factor experiments, the results showed that the optimized technological conditions were as follows: mass fraction of waste fibers $10 \%$, mass fraction of AC foaming agent $3 \%$, mass fraction of APP flame retardant $15 \%$, hot pressing pressure $7 \mathrm{MPa}$, hot pressing temperature 180 , length of waste fibers $20 \mathrm{~mm}$, mixing temperature $175-180$, hot pressing time $8 \mathrm{~min}$, cool-down time $2 \mathrm{~h}$. And, under the optimized technological conditions, the thermal conductivity coefficient was $0.06 \mathrm{~W} /(\mathrm{m} \cdot \mathrm{K})$, the limit oxygen index was $35.82 \%$, the tensile strength was $2.642 \mathrm{MPa}$, and the bending strength was $5.314 \mathrm{MPa}$.

2. The flame retardant mechanism and effect of the waste fiber/polyurethane flame retardant insulation board was analyzed by TGA and residual carbon ratio and the APP flame retardant achieved good flame retardant effect on the flame retardant insulation board. The average diameter of bubble pores was 350 um by SEM and the waste fiber/polyurethane flame retardant insulation board had good and uniform bubble pores, mostly closed bubble pores, thin walls of the bubble pores, round shape of the bubble pores, so it had the excellent thermal insulation properties.

3. The ABAQUS finite element software was used to establish the model of two-dimensional steady-state thermal conduction and the steady temperature distribution nephogram was obtained. The simulated thermal loss was calculated and compared with the measured thermal loss of the sample. The calculated thermal loss of the simulation results was basically the same with the measured thermal loss, which was to say, the thermal insulation properties of the thermal insulation board were feasible by the finite element simulation.

\section{Acknowledgement}

The authors gratefully acknowledge financial support from the Science and Technology Innovation Fund Project of Dalian(201951), Technological Innovation Team Project of Liaoning Province (LT2017017), Natural Science Foundation of Liaoning Province(20170540070)and Liaoning Provincial Education Department Project ( 2017J040).

\section{REFERENCES}

1. Li, P., Ye, H. W., Chen, Y., Zhang, Y., \& Zhao, Y. (2014). Status of recycling of waste textiles at home and abroad. Synthetic Fiber in China, 43(4), 41-45.

2. Ma, L. ( 2013). Textile waste recycling joy and sorrow. China Fiber Inspection, 33(17), 56-57.

3. Qiu, Y. H. ( 2007). Comprehensive utilization of waste textiles. Jiangsu Textile, 26(6), 68-70.

4. Lv, L. H., Bi, J. H., Yu, X., Wang, X., Wei, C. Y., \& Cui, Y. Z. ( 2016) Sound absorption properties of composites made of discarded duck feathers. Tekstil ve Konfeksiyon, 26(2), 153-158.

5. Lv, L. H., Bi, J. H., Ye, F., Qian, Y. F., Zhao, Y. P., Chen, R., \& Su, X. G. (2017). Extraction of discarded corn cob husk fibers and its flame retarded composites. Tekstil ve Konfeksiyon , 27(4) , 408-413.

6. Long, H. S., Xue, P., Ding, Y., \& Liu, X. Y. ( 2014). Study on properties of discarded natural fiber reinforced high density polyethylene composites., China Plastics, 28(11), 95-99.

7. Chen, L., Zou, L., \& Sun, W. G. ( 2017). Preparation and adsorption properties of oil - absorbing materials from pyrolysis of waste flax. Journal of Textile Research, 38(6), 17-22.

8. Zhao, G. ( 2005). Building energy efficiency and energy saving design Science-Technology Information Development and Economy, 15(13), 147-148.

9. Zhang, Z. P., Li, Z., \& Dong, Y. L. ( 2007). The development status and prospect of building thermal insulation wall in buildings. Engineering Mechanics, 24(2), 121-127.

10. Qian, B. Z., \& Zhu, Z. F. ( 2009). Technological progress of building energy-saving thermal insulation materials. Building Energy Efficiency, $37(2), 56-60$.

11. Chen, X. (2015). To analyze the insulation and energy saving of the building perimeter. Resource Economization and Environmental Protection, 33(10), 71.

12. Li, J. (2013). Preparation and application of fiber reinforced composite insulation board (Master's thesis). Available from CNKI and Wanfang database.( DOI:10.7666/d.Y2632186)

13. Zhu, Q. W., Wu, D., \& Zhao, J. P. ( 2012). Research status and progress of external wall insulation materials. New Building Materials, 39(6), 12-15.

14. Yuan, B. (2012). Development and application analysis of thermal insulation glazed hollow bend foaming board (Master's thesis) Available from CNKI and Wanfang database.( DOI:10.7666/d.y2155953)

15. Panyakaew, S., \& Fotios, S. ( 2011). New thermal insulation boards made from coconut husk and bagasse. Energy and Buildings, 43(7), 1732-1739. 
16. Cai, J. P., Liu, L., Chen, X. T., Luo, S. X., Liu, W. H., \& Wang, L. X ( 2012). Sisal fiber reinforced expanded glass beads / phenolic resin composite insulation board. New Building Materials, 39(4), 19-22.

17. Zhao, R. H., Sun, J. J., Cao, J. H., \& Zhao, S. L. ( 2017). Research on green and efficient insulation board. Building Energy Efficiency, 45 (5), 37-41.

18. Zhu, Y., Liu, B., Gao, H., \& Zhang, L. ( 2015). Experimental study on $\mathrm{SiO}_{2}$ aerogel core /polystyrene shell composite flame retardant insulation board. Guangzhou Chemical Industry, 43(1), 78-80,104.

19. Qin, Y., \& Wang, Q. Q. ( 2017). The development of polyurethane materials. China Building Materials Science \& Technology, 26(1), 39-41.

20. Ding, Y. J., Zhu, Z., An, S. Y., \& Cai, L. ( 2010). Preparation and properties of polyurethane foam/wood fiber composite material. Building Energy Efficiency, 38 (11), 62-64.
21. Yu, X., Lv, L. H., Wei, C. Y., Cui, Y. Z., Wang, X., \& Liu, T. ( 2014) Research on sound absorption properties of multilayer structural material based on discarded polyester fiber. Journal of The Textile Institute, 105(10), 1009-1013

22. Chen, S., Chen, H. X., Gao, X. P., \& Long, H. R. ( 2017). Sound absorption properties of polyurethane-based warp-knitted spacer fabric composites. Indian Journal of Fiber \& Textile Research, 42(3), 299-306.

23. Yang, J.N., Li, Z. Q., Wang, L. Y., Liu, X. B., \& Liu, J. S. ( 2010). Foam results and mechanical properties of SGF/PP foam composites. Journal of Nanjing University of Aeronautics and Astronautics, .42(1), 88-92.

24. Liu, Q. J., \& Zeng, L. M. ( 2015). Research of efficient halogen-free flame retardants composite. Fiber Composites, 32(3), 3-6. 